\title{
Diferenças Culturais e de Gênero em Conflitos de Pré-Escolares ${ }^{1}$
}

\author{
Cultural and Gender Differences in Preschool Children's Conflicts
}

\author{
Maria de Lima Salum e Morais ${ }^{* a} \&$ Emma Otta $^{b}$ \\ a Secretaria da Saúde do Estado de São Paulo \& ${ }^{b}$ Universidade de São Paulo
}

\begin{abstract}
Resumo
O estudo compara episódios de conflitos entre crianças de quatro a cinco anos de idade, pertencentes a dois grupos culturais: um de uma grande metrópole (São Paulo) e outro de uma pequena comunidade praiana do estado de São Paulo (Ubatuba). Foram observadas 39 crianças (20 meninas e 19 meninos). Analisaram-se os motivos, as estratégias de oposição, as reações à oposição e o desenlace de conflitos. Nos dois grupos e gêneros, o motivo mais freqüente para os conflitos foi a disputa por brinquedos e as estratégias de resolução pró-sociais mesclaram-se com as coercitivas. Algumas diferenças comportamentais de gênero encontradas nas crianças de São Paulo, diferentemente do que se observou em Ubatuba, assemelharam-se às verificadas em estudos europeus e norte-americanos: os meninos se mostraram mais agressivos e as meninas, mais conciliadoras. As crianças paulistanas apresentaram maior número de táticas verbais, enquanto as estratégias diretas e proximais predominaram entre as ubatubanas. O estudo evidencia a importância de considerar as influências culturais na resolução de conflitos entre crianças.

Palavras-chave: Conflito; diferenças culturais; diferenças de gênero.
\end{abstract}

\begin{abstract}
The study compares conflict episodes of four- to five-year-old children of two cultural groups: one from a big city (São Paulo), and another from a small seashore community in the State of São Paulo (Ubatuba). 20 girls and 19 boys were observed in their free preschool activities. Motives, strategies of opposition, reactions to opposition, and conflicts outcomes were analyzed. The most frequent motive for conflicts was the dispute for toys and other objects. Pro-social and coercive strategies were found in children from both genders and groups. Behavioral differences between genders in the children from São Paulo, differently from what occurred with the children from Ubatuba, were similar to those found in European an North American studies: boys used more aggressive tactics, while girls tended to be more conciliatory. São Paulo's children showed greater number of verbal tactics, while direct and proximal strategies prevailed among Ubatuba's children. The study evidences the importance of considering cultural influences on children's conflict resolution.

Keywords: conflict; cultural differences; gender differences.
\end{abstract}

Observações de pré-escolares em atividades não dirigidas por adultos revelam que o roteiro livre e improvisado da brincadeira pode romper-se a qualquer momento por algo que desperte nas crianças maior atenção, ou pela própria necessidade de ajustamento ao outro, freqüentemente expressa por conflitos e discordâncias (Morais, 1980).

Apesar das inúmeras formas pelas quais se manifesta e dos conteúdos de que se reveste, a atividade lúdica infantil aparece em todas as culturas. Ao mesmo tempo, conflitos interpessoais surgem necessariamente na vida em grupo, permitindo os imprescindíveis ajustes interacionais.

$\mathrm{Na}$ abordagem aos fenômenos da brincadeira e dos conflitos, mantemos a perspectiva de que esses comportamentos revelam componentes universais presentes em toda a espécie humana, ao lado de diversidades advindas de diferentes estilos de criação.

\footnotetext{
1 Pesquisa subvencionada pelo Conselho Nacional de Desenvolvimento Científico e Tecnológico (CNPq).

* Endereço para correspondência: Rua Bernardino Machado, 332, São Paulo, SP, 04722-120. E-mail: salum@isaude.sp.gov.br
}

Consideramos, como Greenfield, Keller, Fuligni e Maynard (2003), que a cultura é um processo socialmente interativo de construção, compreendendo atividades (práticas culturais) e significados (interpretações) partilhados. Ambos os processos são "cumulativos por natureza e ocorrem entre as gerações e dentro delas" (p. 2).

Brincando, a criança adquire e expressa cultura. Tomasello, Kruger e Ratner (1993) destacam um tipo de aprendizagem que se dá através da colaboração entre os pares e que possibilita a construção de algo novo. Ao brincar, a criança cria significados, que podem passar a ser compartilhados pelo grupo de brincadeira, tornando-se um novo elemento da cultura e da história do grupo.

Como afirmam Tomasello et al. (1993), as crianças que aprendem na interação com os companheiros são as que se envolvem com seus parceiros no sentido de planejar em conjunto, de responder às idéias dos outros, de pedir esclarecimentos e de discutir sua atividade conjunta. Na conversa simétrica, aprendem a analisar o pensamento e a perspectiva dos companheiros. Em situações de cooperação ou de conflito, surgem co-construções, em que os parceiros da 
interação fazem um esforço para identificar e interpretar os pensamentos e sentimentos uns dos outros.

Reconhece-se a função do conflito no desenvolvimento da cognição, do entendimento social e da regulação da emoção (C. U. Shantz \& Hartup, 1992). Os conflitos podem levar ao estabelecimento de regras e sistemas de expectativas mútuas que servem para reduzir a incerteza e para promover a coesão grupal, regulando os ajustamentos sociais (Lyons, 1993). Através dos conflitos, adquirem-se informações sobre objetivos, crenças, valores e interesses dos outros. Através das disputas, as crianças adquirem senso de justiça, estabelecem alinhamentos positivos, desenvolvem a autonomia e regulam o afeto (Farris, 2000; Laursen, Finkelstein \& Betts, 2001).

Conflitos são, em última instância, disputas por recursos, sejam eles alimentos, bens, objetos (brinquedos, no caso das crianças), afeto, atenção, território ou controle social. Para manter os benefícios da vida em grupo, as pessoas precisam resolver seus conflitos de interesses. Portanto, mecanismos de resolução de conflitos são componentes críticos da vida social e funcionam para manter a integridade do grupo, pois os desequilíbrios ameaçam sua estabilidade.

Encampamos a definição de Lyons (1993), que entende que os conflitos sociais tendem a ser episódicos, começando com a incompatibilidade entre as ações, objetivos e interesses de dois ou mais participantes e terminando quando as discordâncias são resolvidas, ao menos temporariamente, através de alguma forma de acomodação, condescendência, submissão ou falta de oposição de um ou de ambos os participantes.

Os dados encontrados em diferentes culturas confirmam que, desde cedo no desenvolvimento infantil, aparece a habilidade de competir. Apesar de ser um fenômeno praticamente universal, comportamentos e estratégias empregadas para a obtenção de recursos estão presentes em diferentes graus e variam em estratos ou agrupamentos sociais distintos nas diversas culturas (Charlesworth, 1996; Crystal, Watanabe \& Chen, 2000). Corsaro (1994), por exemplo, verificou que crianças italianas se desentendiam mais do que as norte-americanas, afirmando que os conflitos são um aspecto central da cultura infantil na Itália. O autor também constatou que crianças negras norte-americanas, quando comparadas com as brancas de classe média, apresentavam maior incidência de disputas. Esse achado o levou a sugerir que as crianças negras estudadas construíam sua identidade social, cultivavam as amizades, mantinham e transformavam a ordem social da cultura de companheiros através da oposição e da confrontação.

Bonta (1997), numa extensa revisão das relações humanas em sociedades pacíficas, descreve culturas que são extremamente harmoniosas nos níveis intra e intergrupal, com pouquíssimos casos de violência e praticamente sem conflitos. Y. Gosso (comunicação pessoal, 2002), ao estudar a brincadeira dos índios Parakanã, relata, também, a quase inexistência de conflitos entre essas crianças. Tais procedimentos, típicos de muitas sociedades pacíficas, parecem diferir bastante do que se encontra, de forma geral, nas culturas ocidentais. É muito provável que exista uma ligação entre padrões adultos específicos de relacionamento interpessoal e o manejo de conflitos entre as crianças.

No que concerne às diferenças de gênero, Sheldon (1992) encontrou, em um estudo de conflitos entre tríades de crianças do mesmo sexo numa escola do meio-oeste americano, que o estilo de conflito das meninas era mais brando, com estratégias de discurso mais colaboradoras e com foco no relacionamento, enquanto os conflitos dos meninos caracterizavam-se por um discurso mais carregado, com estratégias mais controladoras e com o foco em si próprios. No mesmo sentido, Underwood, Schockner e Hurley (2001), estudando crianças de cinco a sete anos de idade, verificaram que os meninos usavam mais força física para resolver conflitos do que as meninas. As meninas usavam mais estratégias de abrandamento para solucionar disputas.

Laursen e Hartup (1989), estudando crianças de três a cinco anos de idade, constataram que, em geral, conflitos mais duros e agressivos ocorreram entre meninos e com parceiros do mesmo sexo. Entretanto, os pesquisadores declaram que os resultados foram equívocos quanto à agressão verbal.

Murphy e Einsenberg (1996) verificaram que meninas relatavam mais estratégias construtivas para a resolução dos conflitos e maior preocupação com a afiliação do que seus colegas. No entanto, as autoras também apontam que meninos considerados adequados e com bons níveis de funcionamento social tenderam a mostrar objetivos construtivos e preocupação com os outros na resolução dos conflitos. Diferenças individuais no funcionamento social parecem ter um papel fundamental na forma de as crianças reagirem quando contrariadas.

O objetivo do presente trabalho é comparar o comportamento de meninos e meninas de uma metrópole (São Paulo) com aquele de crianças de uma pequena cidade praiana (Ubatuba, no estado de São Paulo) em relação a quatro momentos dos conflitos: (a) instigação, causa ou motivo; (b) estratégia de oposição; (c) forma de reação à oposição; (d) desenlace.

Os achados sobre o tema, e relatados acima, sugerem que encontraremos diferenças de comportamento entre os gêneros e entre as culturas. Algumas teorizações, principalmente as de Keller (1998) e de Lock (2000), ajudamnos a explicar possíveis diferenças atribuíveis a estilos diversos de criação das crianças.

Keller (1998) sugere dois estilos fundamentais de criação: o distal e o proximal. Segundo a autora, as culturas ocidentais promovem a autonomia precoce e a estrutura diádica-distal exclusiva, dirigida para controlar o ambiente - resultando numa definição do self como agente -, enquanto as não ocidentais envolvem cuidado múltiplo e coativo e contato corporal íntimo - acarretando um conceito de self como co-agente.

Outra distinção importante entre os estilos culturais de comunicação é indicada por Lock (2000) e diz respeito à forma como se estruturam as sociedades. A composição das relações entre as pessoas e as propriedades dos discursos e práticas em que elas se envolvem constituem as condições 
que as capacitam a descobrir as implicações dos sistemas de símbolos, relações sociais e práticas de discurso que constituem seu modo de vida. Dessa forma, segundo Lock, léxicos com relativamente poucos termos tendem a ocorrer em conjunção com culturas relativamente simples, enquanto léxicos com muitos termos tendem a ocorrer associados a culturas e a tecnologias complexas. Os sistemas referenciais se tornam mais elaborados à medida que as sociedades aumentam em complexidade.

Levando-se em conta a extensão territorial do Brasil, sua diversidade sociodemográfica e histórico-cultural, podemos falar em pluralidade cultural brasileira. Assim também pondera Oliveira (1982), ressaltando os contrastes da cultura brasileira. Conway, Ryder, Tweed e Sokol (2001) comentam que a variação regional no interior de uma mesma nação é um precioso recurso para analisar relações interculturais que são normalmente estudadas em nível internacional. Da mesma forma, Tudge et al. (2006) consideram que diferenças regionais dentro de um mesmo país, assim como realidades socioeconômicas diversas, podem ser elementos que determinam a formação de culturas distintas. Por essa razão, neste trabalho, usamos o termo cultura para designar diferentes modos de vida e estilos de criação de dois grupos de crianças.

Supomos que o comportamento do grupo de crianças observadas em uma creche universitária de São Paulo cujos pais convivem em um ambiente presumivelmente mais competitivo e tendem a manter relações mais distais com seus filhos, estimulando-lhes a autonomia e o raciocínio lógico-abstrato - apresente diferenças em relação ao comportamento do grupo de crianças de uma pré-escola pública de Ubatuba - cujos pais, vivendo numa comunidade pequena, ocupam-se de funções manuais e, possivelmente, incentivam em seus filhos predominantemente o desenvolvimento do raciocínio prático e a solução rápida para problemas concretos ${ }^{2}$.

\section{Método}

\section{Participantes}

Foram observadas 39 crianças de dois grupos culturais, assim caracterizados:

1. grupo da cidade de São Paulo: composto de 20 crianças (dez meninos e dez meninas), com quatro anos e onze meses de idade em média (variando de quatro anos e cinco meses até cinco anos e quatro meses), de uma creche de universidade pública do município de São Paulo, capital do Estado de São Paulo;

2. grupo da cidade de Ubatuba: formado por 19 crianças (nove meninos e dez meninas), com cinco anos e quatro meses de idade em média (variando de quatro anos e onze meses a cinco anos e dez meses), de uma préescola pública do município de Ubatuba, no Litoral Norte do Estado de São Paulo.

\footnotetext{
${ }^{2}$ Informações mais detalhadas a respeito dos grupos estuda-
} dos encontram-se em Morais (2004).
As crianças de Ubatuba eram moradoras da Praia de Itamambuca e adjacências, que dista cerca de $13 \mathrm{~km}$ do centro da cidade. Os pais das crianças observadas eram, em sua maioria, caseiros ou jardineiros e as mães, diaristas ou apenas donas-de-casa. Havia alguns poucos artesãos e trabalhadores que viviam de pequenos serviços esporádicos, em geral na construção civil. A maior parte das crianças era nascida no município de Ubatuba e morava na praia ou no sertão ${ }^{3}$ de Itamambuca e vizinhanças (praia e sertão do Prumirim e do Félix e sertão da Casanga).

A maioria das crianças observadas na cidade de São Paulo habitava em bairros da zona oeste do município, onde também se situava a creche em que passavam o dia. Havia diversidade de nível sócio-econômico entre os participantes deste grupo. Seus pais eram, na maioria, funcionários administrativos e técnicos de nível médio; havia, também, uma minoria de pais trabalhadores não especializados e de professores e alunos de pós-graduação da universidade.

Os pais das crianças observadas assinaram um termo de consentimento autorizando sua participação na pesquisa e o uso de sua imagem para fins científicos.

\section{Procedimento}

Utilizou-se o método de observação por sujeito focal (Altmann, 1974). Todas as crianças foram observadas nos horários de atividade livre. Cada sessão de observação tinha cinco minutos de duração, sendo dividida em períodos de um minuto. A ordem em que as crianças foram observadas foi aleatória. Seguiu-se a regra de não repetir observações de uma mesma criança no mesmo dia. O número médio de sessões foi oito no grupo de São Paulo (variando de seis a nove) e seis no grupo de Ubatuba (variando de seis a oito).

Em ambas as unidades educacionais, a interferência das educadoras nos conflitos era mínima, pois procuravam deixar que as crianças resolvessem por si próprias suas desavenças, a não ser quando sua mediação era solicitada. Embora as educadoras deixassem as crianças bastante livres, nos raros episódios mais duradouros e violentos de agressão física, a educadora interferia quando estava atenta. Houve dois casos em que a pesquisadora (primeira autora) interferiu, pois notou que crescia a violência entre as crianças envolvidas e que a educadora não o percebera por estar distante ou ocupada com outros afazeres.

Estabelecidas as categorias, houve um período de treino com dois pesquisadores experientes. Após o treino, calculou-se a fidedignidade relativa às categorias utilizadas para codificar os comportamentos observados. A fidedignidade foi computada para pares de pesquisadores com base em 30 minutos de registro selecionados ao acaso. Os índices

${ }^{3}$ Os ubatubanos costumam referir-se a seus locais de morada como cidade, praia, costão ou costeira e sertão. A cidade é onde se dá a principal concentração populacional, de comércio e de serviços. A praia é a região plana, próxima da orla marítima. Costeira é a região que confronta diretamente com o oceano e onde não há praias. O sertão é a região mais escassamente povoada, que se situa entre a orla marítima e a Serra do Mar (Marcílio, 1986). 
Kappa entre os pares de juízes variaram de 0,78 a 0,90. Todos os testes estatísticos usados no trabalho basearamse em Green, Salkind e Akey (2000).

\section{Categorias Utilizadas}

1. Motivos aparentes. Consideramos motivos as causas instigadoras ou desencadeadoras do conflito. Foram classificados dentro das seguintes categorias: brincadeira excede limites; disputa por brinquedos ou outros objetos; disputa por espaço, por ordem, vez ou lugar na fila; disputa por autoridade, controle, por imposição de regras, por posição ou papel; disputa para conseguir atenção, aprovação de um companheiro ou adulto; ser agente ou alvo de ameaça, provocação ou de agressão aparentemente injustificada; e motivo ignorado.

2. Estratégias de oposição. As estratégias de oposição são os comportamentos que indicam que um conflito de interesses ou de intenções se iniciou. Podem ser: (a) estratégias não coercitivas - argumentação contrária ou de defesa de direitos, opiniões e interesses; negativa simples; movimento de retenção ou de oposição não agressivo; (b) estratégias coercitivas - toma ou tenta tirar objeto; agride fisicamente; agride verbalmente, zomba; ameaça retirar a amizade; chantageia; faz imposição verbal.

3. Respostas à oposição. As respostas ou reações à oposição são os comportamentos do agente ou do alvo do conflito que se sucedem a uma contraposição de idéias, intenções ou interesses, conforme enunciado no tópico anterior. Pode ou não coincidir com o desenlace. Caso seja também o desfecho, o comportamento foi computado nas duas categorias (resposta à oposição e desenlace). As respostas à oposição podem ter caráter coercitivo, não coercitivo ou evitativo: (a) táticas diretas, não coercitivas - contraposição verbal simples; movimento de retenção ou de oposição não agressivo; insiste; usa táticas de sedução (argumenta, sugere); (b) táticas coercitivas - toma ou tenta tirar objeto; agride fisicamente; agride verbalmente, zomba; ameaça agredir fisicamente; ameaça retirar amizade; faz chantagem; (c) táticas evitativas - referem-se aos comportamentos através dos quais a criança dá uma resposta passiva ou indireta à oposição de outra: isola-se, afasta-se da situação; cede ao desejo do outro; chora; substitui o objeto ou a brincadeira; disfarça, nega intenção inicial.

4. Desenlace ou desfecho. Desenlace ou desfecho é a forma como cessa o conflito num determinado momento. Os desfechos foram classificados como afiliativos, intermediados por terceira parte, impostos ou coercitivos, evitativos e resultantes de neutralização da disputa: (a) desenlace afiliativo - convite para brincar, contato corporal afetuoso, pedido de desculpas, auto-ridicularização, oferta simbólica (ceder o lugar na fila ou o papel na brincadeira, por exemplo) e conciliação; (b) desfecho imposto ou coercitivo: uma parte envolvida usa agressão física ou verbal, utiliza força física ou faz imposição verbal para fazer cessar o conflito; (c) desenlace evitativo - uma parte retira-se do local ou da situação de conflito, isola-se ou o ignora, encerrando-o; (d) intermediação de terceira parte: uma terceira parte (colega ou adulto) interfere para fazer cessar o desentendimento. A intervenção pode ter sido solicitada pelas partes em conflito ou originar-se de iniciativa da terceira parte; (e) neutralização do conflito - uma das partes ou todos os colegas envolvidos na disputa, sem que haja razão aparente nem negociação, desistem de se opor, desviam o foco da atenção para outro alvo ou passam a brincar junto ou com outro companheiro; (f) não houve desenlace durante o período observado.

5. Número de elos do conflito. Considera-se número de elos ou unidades de um conflito o número de comportamentos de oposição ou de reação a essa que ocorre até que haja o desfecho, num determinado período de tempo. Se houvesse mudança de foco, de crianças envolvidas ou de motivo da disputa, computava-se um novo conflito.

\section{Resultados}

\section{Freqüência de Conflitos}

Foram observados 166 conflitos no total dos dois grupos. Estão dispostos na Tabela 1 os valores absolutos, o número médio de conflitos por hora e as freqüências relativas ao tempo de observação, conforme grupo cultural e gênero.

Tabela 1

Número de Conflitos Observados, Média de Conflitos por Hora e Freqüências de Conflitos Relativas ao Tempo de Observação nos Dois Grupos Culturais e Gêneros

\begin{tabular}{lccccc}
\hline \multirow{2}{*}{ Conflitos } & \multicolumn{2}{c}{ Meninos } & \multicolumn{2}{c}{ Meninas } & Total \\
\cline { 2 - 6 } & São Paulo & Ubatuba & São Paulo & Ubatuba \\
\hline Número absoluto & 51 & 29 & 46 & 40 & 166 \\
Conflitos por hora & 7,8 & 5,8 & 6,8 & 7,0 & 6,9 \\
Freqüência relativa & $0,13 \pm 0,02$ & $0,10 \pm 0,03$ & $0,12 \pm 0,02$ & $0,12 \pm 0,02$ & 0,11 \\
\hline
\end{tabular}


A ANOVA calculada para testar o efeito de origem e de gênero sobre o número de conflitos, relativizados pelo tempo de observação, não revelou diferenças significativas. Verificou-se, entretanto, ligeira diferença nas médias observadas: os meninos de Ubatuba revelaram menor número de conflitos do que os garotos de São Paulo e do que as meninas dos dois grupos; as meninas dos dois grupos culturais apresentaram igual frequiência de conflitos.

\section{Número de Elos}

A ANOVA calculada para testar o efeito de origem e de gênero sobre a proporção entre número de elos e número de conflitos revelou efeito estatisticamente significativo de gênero $\left(\mathrm{F}_{1,35}=3,998, \mathrm{p}=0,05\right)$, marginalmente significativo de origem $\left(\mathrm{F}_{1,35}=2,660, \mathrm{p}<0,10\right)$ e de interação entre ambos os fatores $\left(\mathrm{F}_{1,35}=2,712, \mathrm{p}<0,10\right)$. Tanto meninos quanto meninas de Ubatuba apresentaram a mesma média de elos por conflito $(2,8)$; os meninos de São Paulo revela- ram 2,8 elos por conflito e as meninas, 3,9. Constata-se, portanto, que a diferença estatística verificada ocorreu devido ao maior número de elos apresentados pelas meninas de São Paulo.

\section{Motivos}

A Tabela 2 mostra a distribuição dos diversos motivos de conflitos por grupo cultural e gênero. Observa-se, em todos os grupos, predominância da disputa por objetos. Em seguida, para as meninas dos dois grupos, aparece disputa pela vez, espaço ou lugar na fila e, em terceiro lugar, disputa por autoridade ou controle social. Entre os meninos ubatubanos, após disputas por objeto, ocorrem as desavenças por ser agente ou alvo de agressão aparentemente injustificada e disputas por controle social. Entre os meninos de São Paulo, há uma distribuição uniforme de disputas por controle social e por ser agente ou alvo de agressão aparentemente injustificada.

Tabela 2

Porcentagens de Tipos de Motivos de Conflito por Grupo Cultural e Gênero

\begin{tabular}{|c|c|c|c|c|}
\hline \multirow{2}{*}{ Motivos } & \multicolumn{2}{|c|}{ Meninos } & \multicolumn{2}{|c|}{ Meninas } \\
\hline & $\begin{array}{c}\text { S. Paulo } \\
\%\end{array}$ & $\begin{array}{c}\text { Ubatuba } \\
\%\end{array}$ & $\begin{array}{l}\text { S. Paulo } \\
\%\end{array}$ & $\begin{array}{c}\text { Ubatuba } \\
\%\end{array}$ \\
\hline Brincadeira excede limites & 08 & 0 & 10 & 03 \\
\hline Disputa por objetos & 59 & 34 & 49 & 43 \\
\hline Disputa por espaço ou vez & 04 & 11 & 19 & 30 \\
\hline Disputa por controle, autoridade & 11 & 21 & 17 & 15 \\
\hline Agente ou alvo de agressão injustificada & 11 & 26 & 01 & 09 \\
\hline Motivo acidental & 0 & 0 & 02 & 0 \\
\hline Motivo ignorado & 07 & 08 & 02 & 0 \\
\hline
\end{tabular}

A MANOVA 2 × 2 calculada para testar efeito de origem e de gênero sobre as diversas modalidades de motivo de conflito revelou apenas efeito marginalmente significativo de gênero (Lambda de Wilks $=0,701, F_{6,30}=2,131, p=$ 0,79). Análises univariadas subseqüentes revelaram efeito de gênero sobre: disputa de espaço, vez ou lugar na fila $\left(F_{1,35}=6,860, p<0,05\right)$, com as meninas excedendo os meninos neste aspecto; ameaça e agressão aparentemente injustificadas $\left(F_{1,35}=4,427, p<0,05\right)$ e motivos ignorados $\left(F_{1,35}=3,224, p<0,10\right)$, aspectos em que meninos superaram as meninas. Embora o motivo tivesse sido considerado ignorado quando não havia, no período de observação, antecedentes que justificassem o conflito, é possível suporse que, assim como os conflitos aparentemente injustifi- cados, as disputas desencadeadas por motivos ignorados tenham sido causadas por situações não imediatamente anteriores às observadas.

\section{Estratégias de Oposição}

Para verificar a distribuição das diversas estratégias de oposição, dividiu-se cada uma das estratégias adotadas pela criança focal pelo total de estratégias de oposição empregadas por ela. Agrupando-se as proporções de estratégias afiliativas num bloco e coercitivas em outro, obtêm-se os dados apresentados nas linhas de subtotal da Tabela 3. A MANOVA calculada para testar efeito de origem e de gênero sobre os dois tipos de estratégia não revelou resultados estatisticamente significativos. 
Tabela 3

Porcentagens das Diversas Estratégias de Oposição por Grupo Cultural e Gênero

\begin{tabular}{|c|c|c|c|c|}
\hline \multirow{2}{*}{ Estratégias de oposição } & \multicolumn{2}{|c|}{ Meninos } & \multicolumn{2}{|c|}{ Meninas } \\
\hline & $\begin{array}{c}\text { S. Paulo } \\
\%\end{array}$ & $\begin{array}{c}\text { Ubatuba } \\
\%\end{array}$ & $\begin{array}{c}\text { S. Paulo } \\
\%\end{array}$ & $\begin{array}{c}\text { Ubatuba } \\
\%\end{array}$ \\
\hline \multicolumn{5}{|l|}{ Não coercitivas } \\
\hline Argumentação contrária ou em defesa & 10 & 0 & 08 & 08 \\
\hline Negativa simples & 04 & 10 & 20 & 11 \\
\hline Movimento de retenção não agressivo & 04 & 07 & 05 & 02 \\
\hline Subtotal - não coercitivas & 18 & 17 & 33 & 21 \\
\hline \multicolumn{5}{|l|}{ Coercitivas } \\
\hline Tira ou tenta tirar objeto & 30 & 35 & 17 & 35 \\
\hline Agride fisicamente & 30 & 39 & 14 & 33 \\
\hline Agride verbalmente, zomba & 01 & 0 & 05 & 0 \\
\hline Ameaça agredir fisicamente & 04 & 06 & 06 & 0 \\
\hline Faz chantagem & 03 & 0 & 10 & 0 \\
\hline Faz imposição verbal & 14 & 03 & 15 & 11 \\
\hline Subtotal - coercitivas & 82 & 83 & 67 & 79 \\
\hline
\end{tabular}

Verificando-se as estratégias de oposição em separado (Tabela 3), observa-se, entre as crianças ubatubanas, quando comparadas às de São Paulo, uma diversidade menor de estratégias adotadas. As táticas mais comumente empregadas pelas crianças de Ubatuba e pelos meninos de São Paulo foram agredir fisicamente e tirar objetos. Entre as meninas paulistanas, encontra-se a negativa simples como estratégia mais freqüentemente usada e maior diversidade de estratégias de oposição.

A MANOVA 2 x 2 calculada para testar efeitos de origem e de gênero sobre as diversas estratégias de oposição revelou efeito significativo de origem sobre essas categorias (Lambda de Wilks $=0,557 ; F_{8,28}=2,788, p<0,05$ ). Análises univariadas subseqüentes mostraram efeito marginalmente significativo de origem sobre as categorias agredir verbalmente ou zombar $\left(F_{1,35}=3,675, p<0,10\right)$ e ameaçar retirar a amizade $\left(F_{1,35}=3,871, p<0,10\right)$. Nesses comportamentos, as crianças de São Paulo superaram as de Ubatuba, mesmo porque, entre essas últimas, não se registraram ocorrências dessas categorias.

Embora fosse esperado, mediante comparação com dados da literatura, que os meninos excedessem as meninas na utilização de agressão física como estratégia de oposi- ção, não foram constatadas diferenças estatisticamente significativas nesse aspecto quando se analisam os dois grupos. Entretanto, se analisarmos separadamente o grupo de São Paulo, essa expectativa se confirma: meninos excederam suas colegas em táticas agressivas $\left(t_{18}=2,794, p<0,05\right)$.

\section{Respostas à Oposição}

Para comparar as respostas à oposição dos dois grupos culturais e gêneros, calculou-se, inicialmente, para cada criança, a razão entre os diversos tipos de reação à oposição e o total de respostas à oposição. Em seguida, foram agrupadas as respostas de tipo coercitivo, não coercitivo e evitativo (Tabela 4). Procedeu-se, então, ao cálculo de uma MANOVA 2 × 2 para apurar efeitos de origem e de gênero sobre essas três modalidades de reação. Obteve-se apenas efeito marginalmente significativo de interação entre origem e gênero (Lambda de Wilks $=0,876, F_{2,34}=2,408, p=$ $0,10)$. Análises univariadas subseqüentes indicaram que este efeito ocorreu em relação às respostas não coercitivas $\left(F_{1,35}=4,795, p<0,05\right)$. Pela Tabela 4 , observa-se que as meninas de Ubatuba superaram seus colegas, enquanto garotos e garotas paulistanas tiveram escores semelhantes neste tipo de reação. 
Tabela 4

Porcentagens de Estratégias de Reação à Oposição por Grupo Cultural e Gênero

\begin{tabular}{|c|c|c|c|c|}
\hline \multirow{2}{*}{ Reações à oposição } & \multicolumn{2}{|c|}{ Meninos } & \multicolumn{2}{|c|}{ Meninas } \\
\hline & $\begin{array}{c}\text { S. Paulo\% } \\
\%\end{array}$ & $\begin{array}{c}\text { Ubatuba\% } \\
\%\end{array}$ & $\begin{array}{c}\text { S. Paulo } \% \\
\%\end{array}$ & $\begin{array}{c}\text { Ubatuba\% } \\
\%\end{array}$ \\
\hline \multicolumn{5}{|l|}{ Não coercitivas } \\
\hline Contraposição verbal simples & 14 & 14 & 09 & 23 \\
\hline Movimento de oposição não agressivo & 02 & 0 & 03 & 03 \\
\hline Insiste & 02 & 0 & 10 & 19 \\
\hline Usa tática de sedução & 0 & 0 & 01 & 0 \\
\hline Argumenta & 11 & 03 & 05 & 03 \\
\hline Subtotal - não coercitivas & 29 & 17 & 28 & 48 \\
\hline \multicolumn{5}{|l|}{ Coercitivas } \\
\hline Tira ou tenta tirar objeto & 10 & 08 & 07 & 08 \\
\hline Agride fisicamente & 06 & 24 & 0 & 13 \\
\hline Agride verbalmente, zomba & 0 & 0 & 0 & 02 \\
\hline Ameaça agredir fisicamente & 0 & 0 & 02 & 0 \\
\hline Faz chantagem & 07 & 07 & 09 & 02 \\
\hline Faz imposição verbal & 03 & 0 & 02 & 0 \\
\hline Subtotal - coercitivas & 26 & 39 & 20 & 25 \\
\hline \multicolumn{5}{|l|}{ Evitativas } \\
\hline Isola-se, afasta-se & 02 & 14 & 01 & 04 \\
\hline Cede & 22 & 16 & 45 & 21 \\
\hline Chora & 21 & 12 & 06 & 02 \\
\hline Substitui objeto ou brincadeira & 0 & 02 & 0 & 0 \\
\hline Subtotal - evitativas & 45 & 44 & 52 & 27 \\
\hline
\end{tabular}

Verificando-se a distribuição das diversas reações à oposição separadamente por grupo cultural e gênero (Tabela 4), observa-se, nos dois grupos culturais e gêneros, alta frequiência das respostas de ceder ao desejo do outro e de negativa simples. Entretanto, entre os meninos ubatubanos prevaleceu a agressão física e, entre suas colegas, a insistência também apareceu com grande freqüência.

Tomando-se as proporções de respostas à oposição isoladamente nas diversas categorias em que foram classificadas, procedeu-se a três análises multivariadas (MANOVAs) 2 x 2: uma para as categorias de respostas coercitivas, outra para as não coercitivas e uma terceira para os comportamentos classificados como reações evitativas. A MANOVA calculada para apurar efeito de origem e de gênero sobre as categorias de respostas não coercitivas revelou efeito significativo de gênero (Lambda de Wilks = $\left.0,691, F_{5,31}=2,772, p<0,05\right)$. Análises univariadas subseqüentes indicaram que tal efeito se deu sobre a categoria "insiste" $\left(F_{1,35}=8,709, p<0,01\right)$, em que as meninas superaram os meninos.

A MANOVA calculada para apurar efeitos de origem e de gênero sobre as categorias de respostas coercitivas revelou efeito positivo, marginalmente significativo, de origem (Lambda de Wilks $=0,408, F_{6,30}=2,040, p<0,10$ ). Análises univariadas subsequientes indicaram que tal efeito se deu sobre a categoria "agride fisicamente" $\left(F_{1,35}=7,216\right.$, $p<0,01)$, em que as crianças de Ubatuba superaram as de São Paulo.

A MANOVA para apurar efeito de origem e gênero sobre respostas evitativas revelou efeitos positivos, marginalmente significativos, de origem (Lambda de Wilks = $0,776, F_{432}=2,312, p<0,10$ ) e de gênero (Lambda de Wilks $\left.=0,795, F_{4,32}=2,060, p=0,10\right)$. Análises univariadas subseqüentes indicaram efeitos marginalmente significativos de origem sobre as categorias "isola-se" ou "afasta-se" $\left(F_{1,35}\right.$ $=3,492, p<0,10)$ e "cede" $\left(F_{1,35}=3,279, p<0,10\right)$, e de gênero sobre as categorias "cede" $\left(F_{1,35}=3,082, p<0,10\right) \mathrm{e}$ "chora" $\left(F_{1,35}=3,880, p<0,10\right)$. Na categoria "afasta-se", as crianças de Ubatuba superaram as paulistanas e essas excederam as primeiras na categoria "cede". Quanto às diferenças de gênero, as meninas excederam os meninos na categoria "cede", e esses as superaram na categoria "chora".

\section{Desenlaces}

Verificou-se que, para todas as crianças, com exceção dos meninos de São Paulo, os expedientes mais utilizados para o desenlace de episódios de conflito foram afiliativos e de neutralização do conflito (Tabela 5). Os meninos de São Paulo apresentaram maior proporção de desfechos coercitivos do que afiliativos. 
Tabela 5

Porcentagens de Tipos de Desenlace por Grupo Cultural e Gênero

\begin{tabular}{lcccc}
\hline \multirow{2}{*}{ Desenlaces } & \multicolumn{2}{c}{ Meninos } & \multicolumn{2}{c}{ Meninas } \\
\cline { 2 - 5 } & $\begin{array}{c}\text { S. Paulo } \\
\%\end{array}$ & $\begin{array}{c}\text { Ubatuba } \\
\%\end{array}$ & $\begin{array}{c}\text { S. Paulo } \\
\%\end{array}$ & $\begin{array}{c}\text { Ubatuba } \\
\%\end{array}$ \\
\hline Afiliativo & 13 & 37 & 26 & 30 \\
Imposto ou coercitivo & 20 & 0 & 14 & 09 \\
Evitativo & 05 & 0 & 05 & 15 \\
Intermediação de terceira parte & 08 & 24 & 09 & 10 \\
Neutralização do conflito & 30 & 25 & 26 & 27 \\
Não há desenlace no período & 24 & 14 & 20 & 09 \\
\hline
\end{tabular}

A MANOVA aplicada para se verificar efeitos de origem e de gênero sobre os tipos de desfecho não revelou resultados significativos.

\section{Discussão}

Apesar das pequenas diferenças encontradas, consideraremos que os dois grupos e gêneros apresentaram aproximadamente o mesmo número de conflitos. Tendo em vista as funções do conflito na regulação social, podemos supor que os dois grupos a exerçam igualmente e que possíveis diferenças estabeleçam-se na análise mais detalhada das modalidades de conflito.

$\mathrm{O}$ achado da freqüência semelhante de conflitos entre meninos e meninas dos dois grupos não se coaduna com a maioria dos dados encontrados na literatura internacional. Laursen e Hartup (1989), Miller, Danaher e Forbes (1986) e D. W. Shantz (1986), por exemplo, encontraram maior número de conflitos entre meninos do que entre meninas. Estudos mais recentes, porém, como os de Hawley (2002) e de Murphy e Einsenberg (1996, 2002), tendem a relativizar as particularidades de gênero, evidenciando que aspectos que difeririam entre meninos e meninas estariam mais relacionados a estratégias que ocorrem durante os conflitos e a seus objetivos do que a sua freqüência.

Observamos que os meninos ubatubanos apresentaram incidência ligeiramente menor de conflitos. Tal fato pode estar relacionado com a maior freqüência de zombaria apresentada por eles (computada, porém não relatada neste trabalho), o que indicaria, segundo constataram Keltner, Capps, Kring, Young e Heerey (2001), que a zombaria pode ter um efeito na prevenção de conflitos.

Miller et al. (1986) atribuem as diferenças de gênero relativas ao número de conflitos ao tipo de atividades escolhidas por meninos e por meninas: as atividades preferidas por meninos, mais movimentadas e menos organizadas, dariam maior margem a desentendimentos. Pelas características mais solitárias do comportamento de alguns meninos ubatubanos e mais ativas de suas colegas, constatamos, no grupo de Ubatuba, o inverso do que se verifica nos estudos de crianças euro-americanas: embora de forma estatisticamente não significativa, as meninas conflitaram mais do que seus colegas do sexo masculino. Entre as crianças paulistanas, contudo, eventuais diferenças podem dizer mais respeito à "anatomia" dos conflitos, ou seja, à forma como se configuraram as disputas do que à sua freqüência.

Quanto ao número de conflitos constatados, D. W. Shantz (1987) relata estudos com crianças de 18 a 62 meses, que encontraram oito conflitos por hora em média, variando esse número de quatro a dezessete. Essa freqüência é compatível com nossos dados (6,9 conflitos por hora, em média).

A constatação de uma maior proporção de elos por conflito por parte das meninas de São Paulo evidencia que, durante as disputas, elas apresentaram maior número de trocas, envolvendo predominantemente verbalizações. Esse dado está de acordo com os resultados da maior parte dos estudos sobre diferenças sexuais em conflitos, que destacam maior negociação por parte das meninas e mais soluções impostas e unilaterais por parte dos meninos (Hawley, 2002; Murphy \& Einsenberg, 2002).

Quanto aos motivos instigadores dos conflitos, a grande incidência de disputas de objetos reflete provavelmente o nível de desenvolvimento das crianças estudadas, indicando a importância da posse de brinquedos e de outros objetos para elas. D. W. Shantz (1987) relata estudos que encontraram que, em crianças de três a cinco anos de idade, a mais freqüente causa de disputas era por objetos.

Os meninos superaram as meninas em conflitos por motivo ignorado e por ameaças ou agressões aparentemente injustificadas. Embora a categoria motivo ignorado pudesse ser decorrente de limitações do método - que, em alguns casos, só permitiu o registro de uma parte dos conflitos -, sua maior freqüência, ao lado das ameaças e agressões aparentemente sem motivo, pode indicar fenômeno de significado semelhante. Há numerosos estudos que demonstram que meninos usam mais agressividade em conflitos do que as meninas (Chung \& Asher, 1996; Miller et al., 1986; Otta \& Souza, 1999; Rose \& Asher, 1999; D. W. Shantz, 1986).

É também interessante ressaltar que, por dados de literatura que acentuam a importância da hierarquia em grupos de meninos (Harris, 1998), poder-se-ia esperar que eles apresentassem mais disputas por controle e por dominação social do que as meninas. Tal fato não se verificou nos 
grupos estudados, o que pode indicar que essa tendência não é tão generalizada ou que se está tornando menos típica como característica de gênero nos tempos atuais ou, ainda, - hipótese que é mais provável - que as meninas também tenham passado a se preocupar mais com o controle social.

Nos grupos estudados, tanto em relação às estratégias de oposição quanto às de reação à oposição, constatou-se uma tendência de as meninas empregarem mais estratégias afiliativas do que os meninos - como se evidencia em muitos trabalhos (Chung \& Asher, 1996; Hartup, French, Laursen, Johnston \& Ogawa, 1993; Miller et al., 1986; Rose \& Asher, 1999).

Fato digno de nota foi a predominância de estratégias de oposição coercitivas sobre as afiliativas em todos os grupos. Esse resultado revela que, entre as crianças observadas, a maioria dos conflitos não se instalou através do diálogo e sim de medidas unilaterais. Com efeito, D. W. Shantz (1987) relata que as soluções bilaterais surgem a partir dos oito anos de idade. Contudo, entre nossas crianças já aparecem algumas soluções bilaterais, sugerindo preocupação com os sentimentos e com a reação do parceiro. Nossos dados são mais compatíveis com o ponto de vista de Hawley (2002), que sugere que, em crianças de três a seis anos, táticas coercitivas e pró-sociais estão altamente relacionadas na efetividade de controle de recursos.

Se analisarmos apenas o grupo de São Paulo, confirmase a expectativa de maior agressão física entre os meninos. Já no grupo de Ubatuba, as meninas aproximaram-se dos meninos no uso desse expediente, indicando comportamento menos prototipicamente feminino das ubatubanas, quando comparadas às paulistanas e aos achados de estudos com crianças euro-americanas.

Murphy e Einsenberg (1996) verificaram, em pré-escolares, que a agressão física era relativamente rara (ocorrendo entre $5 \%$ e $20 \%$ em episódios de conflito), predominando, entre essas crianças, estratégias verbais de oposição. D. W. Shantz (1987) constatou que, em crianças de cinco anos e meio, a maior parte dos conflitos não envolvia agressão: $49 \%$ das oposições eram arrazoados sobre a divergência e $32 \%$, negativas simples. Os subgrupos aqui estudados, com exceção das meninas de São Paulo, exibiram um nível maior de agressão do que relatam essas autoras.

A distribuição de estratégias de oposição revela tendência das crianças de Ubatuba a utilizarem mais táticas envolvendo contato proximal (agredir fisicamente, tirar o objeto) do que as de São Paulo e essas, mais táticas verbais (impor, agredir verbalmente e ameaçar retirar a amizade) do que as primeiras. É notória a semelhança de freqüência de uso de estratégias físicas entre meninas e meninos ubatubanos como reação à provocação de conflitos.

As estratégias utilizadas pelo grupo de São Paulo estão mais de acordo com os dados obtidos em trabalhos com crianças euro-americanas: meninas usariam mais táticas verbais e meninos, mais expedientes físicos diretos (Murphy \& Einsenberg, 1996; Rose \& Asher, 1999). É importante lembrar que certos aspectos que, embora liga- dos à cultura, não são inerentes a ela, também podem estar influenciando as estratégias mais diretas e agressivas das crianças ubatubanas. É, por exemplo, amplamente reconhecida a influência exercida por situações de hostilidade vivenciadas em casa sobre o comportamento agressivo das crianças (Ballif-Spanvill, Clayton \& Hendrix, 2003). Soubemos que tal era o caso de um dos meninos mais agressivos do grupo de Ubatuba, cuja família, segundo relato da professora, utilizava expedientes de agressão física em casa, entre pais e filhos e entre irmãos. Evidentemente, as diferenças individuais e o ambiente familiar, embora não tenham sido abordados neste trabalho, exercem grande influência na exibição e na forma de administrar conflitos.

Embora não tenhamos pesquisado diretamente a agressividade das crianças e dos adultos da comunidade de Ubatuba, evidências indiretas, que denotam o comportamento mais rude dos meninos ubatubanos, podem indicar que estejam seguindo modelos dos adultos de sua comunidade.

É também de se destacar a pequena variedade de estratégias de oposição apresentadas pelas crianças ubatubanas, quando comparadas às de São Paulo. É possível que esse achado também esteja relacionado com as diferenças nos códigos de comunicação: crianças de São Paulo valer-seiam de mais respostas alternativas, em virtude da flexibilidade de código que têm que desenvolver, enquanto as de Ubatuba, cuja cultura é mais simples e estampada dentro de valores mais tradicionais, não teriam tanta necessidade de dominar recursos mais indiretos e sofisticados de ataque e de defesa.

Se, nas estratégias de oposição, os meninos paulistanos mostraram maior agressividade física, nos padrões de reação à oposição, exibiram equilíbrio entre respostas coercitivas e não coercitivas, ultrapassando ligeiramente suas colegas nesse último tipo de reação, contrariando expectativas segundo as quais as meninas seriam mais negociadoras e os meninos, mais truculentos e impositivos em suas respostas (Hartup et al., 1993; Miller et al., 1986; D. W. Shantz, 1986). Já as crianças de Ubatuba aproximaram-se mais do esperado, tendo as meninas apresentado, em 50\% dos casos, formas mais afiliativas de responder à oposição. É interessante observar que, nesse aspecto, as garotas ubatubanas aproximaram-se mais do protótipo de reação feminina, contrariando tendências apresentadas nas etapas iniciais das disputas, como se houvesse uma "compensação" pelas formas mais truculentas de iniciar os conflitos e de mostrar oposição. É importante lembrar que muitos dos conflitos cessaram na reação à oposição - o que explicaria também a menor ocorrência de expedientes coercitivos nesse elo da cadeia, quando comparado com o das estratégias de oposição, tendo em vista que as crianças tenderam a apresentar desenlaces mais afiliativos.

Ainda quanto às reações à oposição, verificou-se que as meninas, particularmente as ubatubanas, excederam os meninos na tática de insistência. Encontram-se, na literatura, várias referências à insistência como tática usada durante os conflitos (Eisenberg \& Garvey, 1981; Laursen \& Hartup, 1989). D. W. Shantz (1987) comenta que agressão 
e insistência não costumam ser práticas bem sucedidas na condução de um conflito. Com efeito, algumas de nossas observações demonstram que a insistência pode irritar a criança para a qual a insistente se dirige, dificultando, portanto, que alcance seu objetivo.

A alta incidência da reação de ceder diante da oposição indica que muitos dos conflitos se encerraram após a primeira resposta à oposição, já que não havia por que continuá-los se o adversário cedeu. No que tange às diferenças de gênero, observa-se um aparente paradoxo: enquanto as meninas utilizaram-se mais de insistir e de ceder, os meninos utilizaram-se mais de chorar. Considerando-se que, através de suas respostas, as crianças estão tentando atingir seus objetivos e, ao mesmo tempo, manifestando reações à frustração, insistir significa tentar novamente, ceder representa abandonar seus objetivos e chorar teria um duplo significado: de mostrar que a criança está desapontada, frustrada, mas também disposta a alcançar seus objetivos. Acreditamos que a explicação mais viável para a alta incidência de choro entre os meninos é a de que essa é uma reação mais comum para as táticas pesadas de agressão física, que foram bastante freqüentes como estratégia masculina de oposição.

Como reação à oposição, as crianças de Ubatuba utilizaram-se mais dos expedientes de agredir fisicamente e de afastar-se, novamente duas categorias que envolvem manifestação corporal. As crianças de São Paulo cederam mais do que as de Ubatuba. Pode-se considerar que as conseqüências para o conflito de ceder e de afastar-se são muito semelhantes. Contudo, seu significado para as relações pode ser diferente. Ceder pode significar preocupar-se com as consequiências dos conflitos para o relacionamento; afastar-se pode significar apenas desistir de levar adiante o conflito. Nessa medida, podemos considerar que as crianças de São Paulo, em especial as meninas, comportaramse dentro das expectativas de que meninas tenderiam a se preocupar mais com a preservação das relações.

Outro aspecto que merece ser comentado foi a maior freqüência de agressão física como reação à oposição entre meninos e meninas de Ubatuba, quando comparados especialmente com as meninas de São Paulo. No elo inicial dos conflitos, todavia, meninos de São Paulo mostraram-se também bastante agressivos. Se maior agressividade explícita por parte dos meninos é esperada em vista de dados já comentados da literatura - meninas são mais pró-sociais e meninos, mais agressivos e encorajados a permanecerem firmes em suas posições (Chung \& Asher, 1996) -, o índice relativamente alto de retaliação física apresentado pelas meninas de Ubatuba, quando comparadas com as de São Paulo, é que contraria o esperado. Esse dado é compatível com as características particulares deste subgrupo de meninas.

Maccoby (1996) considera que controlar o resultado do conflito (vencer) seria uma dinâmica prioritariamente masculina. Entretanto, deve-se observar que, entre as ubatubanas, as reações agressivas não se incompatibilizaram com as pró-sociais, o que indica que ambas as reações se manifestaram concomitantemente nas meninas deste grupo peculiar. A esse respeito, Miller et al. (1986) afirmam que, embora haja diferenças, há também grande superposição no comportamento de garotos e garotas e que é possível que haja mais diferenças de ênfase do que de qualidade no comportamento de crianças de ambos os sexos. Segundo os autores, garotos e garotas não são diferentemente manipuladores, apenas usam meios diferentes: meninos utilizam expedientes mais diretos e meninas, mais indiretos.

A alta freqüência de desfechos por neutralização do conflito nos leva a pensar que, para estas crianças, uma forma eficaz de encerrar o conflito tenha sido "mudar de assunto", isto é, não perpetuar o desentendimento até o ponto em que efetivamente houvesse uma resolução. Dell'Aglio e Hutz (2002) também encontraram, em crianças de oito anos, que a distração foi a estratégia mais utilizada para lidar com emoções criadas por situações geradoras de estresse.

As soluções afiliativas foram bastante frequientes em todos os subgrupos, embora em menor proporção entre os meninos paulistanos. Os desfechos afiliativos, somados àqueles por neutralização do conflito, atingiram cerca de $50 \%$ dos casos. Maccoby (1996) argumenta que é possível que a maneira como o conflito é resolvido dentro de uma particular relação diádica seja um produto dos estilos individuais dos dois componentes da díade e que os afetos positivos parecem prevalecer no final.

As demais categorias de desenlace apareceram com pouca freqüência, com exceção de intermediação de terceira parte em Ubatuba. As intermediações observadas foram geralmente solicitadas à professora e partiram principalmente dos meninos ubatubanos. A grande incidência de intermediações de terceira parte a pedido das crianças tanto poderia indicar falta de confiança nos recursos próprios para se defenderem quanto meramente um hábito de recorrer aos adultos para o julgamento de desavenças. É possível que o fato de os meninos ubatubanos usarem mais táticas diretas e pesadas na solução de conflitos tenha acarretado maior necessidade de intervenção por parte do adulto.

Evidencia-se, em suma, que a maior parte de desenlaces dos conflitos foi amigável, encontrando-se predomínio de desfechos coercitivos entre as crianças de São Paulo, quando comparadas às de Ubatuba. É provável que, não se viabilizando uma solução negociada, seja efetivamente mais adaptativo desistir do conflito, ao menos entre os pré-escolares estudados. As conseqüências de uma solução imposta seriam, provavelmente, mais nocivas para as relações interpessoais horizontais, relativamente duradouras, existentes entre estas crianças. Laursen, Hartup e Koplas (1996) argumentam que conflitos que terminam em negociação são mais construtivos do que os resolvidos através de coerção. Pode-se supor que o maior número de desenlaces coercitivos encontrado entre as crianças paulistanas deva-se ao fato de disporem de um número maior de possibilidades de escolha de parceiros de brincadeira, pois brincavam no pátio em conjunto com mais vinte crianças de sua idade; ou seja, os paulistanos poderiam permitir-se mais rompimentos, pois tinham mais parceiros alternativos de relacionamento. 
As conhecidas diferenças de gênero - em que se considera que meninas apresentam soluções mais afiliativas e meninos, mais coercitivas - apareceram apenas no grupo de São Paulo, embora sem significância estatística. Em vista dos dados de literatura comentados, seria de se esperar que os meninos apresentassem mais desfechos coercitivos. Fato surpreendente foi não ter havido nenhum desfecho imposto entre os meninos ubatubanos, que, nos elementos analisados até agora, revelaram-se mais agressivos e truculentos do que os paulistanos. Uma explicação viável para esse resultado é o temor de que suas respostas agressivas, se levadas às últimas conseqüências, pudessem trazer um rompimento que não seria vantajoso para crianças com tão poucas opções de relacionamento no grupo escolar. Poder-se-ia também supor que as táticas mais agressivas dos ubatubanos, sendo culturalmente mais comuns, não seriam levadas tão a sério pelos colegas, que praticamente as ignorariam, no intento de logo pôr fim à situação conflituosa.

A importância das diferenças culturais, inclusive de sua evolução na história das relações interpessoais, é inquestionável. É provável que, quando comparadas com as ubatubanas, as crianças de São Paulo apresentem um padrão de comportamento mais semelhante ao das crianças euro-americanas, em virtude das influências culturais sofridas mais diretamente pelo grupo paulistano - mais exposto a influências da mídia e a valores de uma sociedade mais complexa e globalizada -, muito embora a distribuição dos diversos desfechos entre meninas ubatubanas e paulistanas tenha sido muito semelhante.

Estudamos grupos pequenos em situações particulares. As afirmações feitas aplicam-se a estes grupos peculiares. Para se chegar a assertivas mais categóricas, são necessários estudos com diferentes metodologias, estendendo o levantamento de dados por um tempo maior e estudando diferenças individuais e condições de criação das crianças. Entretanto, o conjunto de dados obtidos neste estudo nos leva a pensar em quão relativa é a regularidade de alguns achados de trabalhos na área da psicologia do desenvolvimento que se pautaram apenas em crianças dos países europeus e norte-americanos, principalmente no que diz respeito a questões de gênero, em que este trabalho evidenciou resultados peculiares em muitos aspectos, atestando a importância de estudos comparativos entre culturas.

\section{Referências}

Altmann, J. (1974). Observational study of behavior sampling methods. Behavior, 49, 227-265.

Ballif-Spanvill, B., Clayton, C. J., \& Hendrix, S. B. (2003). Gender, types of conflict, and individual differences in the use of violent and peaceful strategies among children who have and have no witnessed interparental violence. American Journal of Orthopsychiatry, 73, 141-153.

Bonta, B. D. (1997). Cooperation and competition in peaceful societies. Psychological Bulletin, 121, 299-320.

Charlesworth, W. R. (1996). Co-operation and competition: Contributions to an evolutionary and developmental model. International Journal of Behavioral Development, 19, 25-39.
Chung, T. Y., \& Asher, S. R. (1996). Children's goals and strategies in peer conflict situations. Merrill-Palmer Quarterly, 42, 165-176.

Conway, L. G., Ryder A. G., Tweed, R. G., \& Sokol, B. W. (2001). Intranational cultural variation: Exploring further implications of collectivism within the United States. Journal of CrossCultural Psychology, 32, 681-697.

Corsaro, W. (1994). Discussion, debate and friendship: Peer discourse in nursery schools in the United States and Italy. Sociology of Education, 67, 1-26.

Crystal, D. S., Watanabe, H., \& Chen, R. S. (2000). Preference for diversity in competitive and cooperative contexts: A study of American and Japanese children and adolescents. International Journal of Behavioral Development, 24, 348-355.

Dell'Aglio, D. D., \& Hutz, C. S. (2002). Estratégias de coping e estilo atribucional de crianças em eventos estressantes. Estudos de Psicologia (Natal), 7, 5-13.

Eisenberg, A. R., \& Garvey, C. (1981). Children's use of verbal strategies in resolving conflicts. Discourse Processes, 4, 149-170.

Farris, C. S. P. (2000). Cross-sex peer conflict and the discursive production of gender in a Chinese preschool in Taiwan. Journal of Pragmatics, 32, 539-568.

Green, S. B., Salkind, N. J., \& Akey, T. M. (2000). Using SPSS for Windows: Analyzing and understanding data. New York: Prentice Hall.

Greenfield, P. M., Keller, H., Fuligni, A., \& Maynard, A. (2003). Cultural pathways through universal development. Annual Review of Psychology. Retrieved April 2004, from http:// infotrac.galegroup.com

Harris, J. R. (1998). Diga-me com quem anda... Rio de Janeriro, RJ: Objetiva.

Hartup, W. W., French, D. C., Laursen, B., Johnston, M. K., \& Ogawa, J. R. (1993). Conflict and friendship relations in middle childhood: Behavior in a closed-field situation. Child Development, 64, 445-454.

Hawley, P. (2002). Social dominance and prosocial and coercive strategies of resource control in preschoolers. International Journal of Behavioral Development, 26, 167-176.

Keller, H. (1998). Diferentes caminhos de socialização até a adolescência. Revista Brasileira de Crescimento e Desenvolvimento, 8, 01-14.

Keltner, D., Capps, L., Kring, A. M., Young, R. C., \& Heerey, E. A. (2001). Just teasing: A conceptual analysis and empirical review. Psychological Bulletin, 127, 229 - 248.

Laursen, B., Finkelstein, B. D., \& Betts, N. T. (2001). A developmental meta-analysis of peer conflict resolution. Developmental Review, 21, 423-449.

Laursen, B., \& Hartup, W. W. (1989). The dynamics of preschool children's conflicts. Merrill-Palmer Quarterly, 35, 281-297.

Laursen, B., Hartup, W. W., \& Koplas, A. L. (1996). Towards understanding peer conflict. Merrill-Palmer Quarterly, 42, 76-102.

Lock, A. J. (2000). Phylogenetic time and symbol creation: Where do zopeds come from? Culture \& Psychology, 6, 105 - 129.

Lyons, D. M. (1993). Conflict as a constructive force in social life. In W. A. Mason \& S. P. Mendoza (Eds.), Primate social conflict (pp. 387-408). New York: State University Press.

Maccoby, E. E. (1996). Peer conflict and intrafamily conflict: Are there conceptual bridges? Merrill-Palmer Quarterly, 42, 165-176.

Marcílio, M. L. (1986). Caiçara: Terra e população. Estudo de demografia histórica e da história social de Ubatuba. São Paulo, SP: Paulinas. 
Miller, P. M., Danaher, D. L., \& Forbes, D. (1986). Sex-related strategies for coping with interpersonal conflict in children aged five and seven. Developmental Psychology, 22, 543-548.

Morais, M. L. S. (1980). O faz-de-conta e a realidade social da criança. Dissertação de Mestrado não-publicada, Instituto de Psicologia, Universidade de São Paulo, SP.

Morais, M. L. S. (2004). Conflitos $e(m)$ brincadeiras infantis: Diferenças culturais e de gênero. Tese de Doutorado nãopublicada, Instituto de Psicologia, Universidade de São Paulo, SP.

Murphy, B. C., \& Einsenberg, N. (1996). Provoked by a peer: Children's anger-related responses and their relations to social functioning. Merril-Palmer Quarterly, 42, 103-124.

Murphy, B. C., \& Einsenberg, N. (2002). An integrative examination of peer conflict: Children's reported goals, emotions, and behaviors. Social Development, 11, 534-557.

Oliveira, P. S. (1982). Brinquedos artesanais e expressividade cultural. Vol. 4. Lazer. São Paulo, SP: Serviço Social do Comércio.

Otta, E., \& Souza, I. J. F. C. (1999). Crianças alfa e crianças ômega: Um estudo sobre papéis desempenhados num grupo de pré-escola. In A. M. Carvalho (Ed.), O mundo social da criança: Natureza e cultura em ação (pp. 33-51). São Paulo, SP: Casa do Psicólogo.

Rose, A. J., \& Asher, S.R. (1999) Children's goals and strategies in response to conflicts within a friendship. Developmental Psychology, 15, 69-79.

Shantz, C. U., \& Hartup, W. W. (1992). Conflict and development: An introduction. In C. U. Shantz \& W. W. Hartup (Eds.), Conflict in child and adolescent development (pp. 1-11). Cambridge, MA: Cambridge University Press.

Shantz, D. W. (1986). Conflict, aggression, and peer status: An observational study. Child Development, 57, 1322-1332.

Shantz, D. W. (1987). Conflicts between children. Child Development, 58, 283-305.

Sheldon, A. (1992). Conflict talk: Sociolinguistic challenges to self-assertion and how girls meet them. Merrill-Palmer Quarterly, 38, 95-117.

Tomasello, M., Kruger, A. C., \& Ratner, H. H. (1993). Cultural learning. Behavioral and Brain Sciences, 16, 495-552.

Tudge, J. R. H., Doucet, F., Odero, D., Sperb, T., Piccinini, C. A., \& Lopes, R. S. (2006). A window into different cultural worlds: Young children's everyday activities in the United States, Brazil, and Kenya. Child Development, 77, 1446-1469.

Underwood, M. K., Schockner, A. E., \& Hurley, J. C. (2001). Children's responses to same- and other-gender peers. An experimental investigation with 8-,10-, and 12-year-olds. Developmental Psychology, 37, 362-372. 